\title{
AMENDMENTS
}

\section{Publisher Correction: Inferring whole-genome histories in large population datasets}

Jerome Kelleher (D), Yan Wong, Anthony W. Wohns (D), Chaimaa Fadil (D), Patrick K. Albers (D) and Gil McVean (iD)

Correction to: Nature Genetics https://doi.org/10.1038/s41588-019-0483-y, published online 2 September 2019.

In the version of this article initially published, in Table 1 , the final three numbers in the 'Trees' column were listed as ' $\times 10^{6}$ ' but should have been ' $\times 10^{3}$ '. In addition, the Acknowledgements had omitted support from the UK Biobank Resource, application number 12788. The errors have been corrected in the HTML and PDF versions of the article.

\section{Author Correction: Postzygotic inactivating mutations of $R H O A$ cause a mosaic neuroectodermal syndrome}

Pierre Vabres (1), Arthur Sorlin (1), Stanislav S. Kholmanskikh, Bénédicte Demeer, Judith St-Onge, Yannis Duffourd, Paul Kuentz @ , Jean-Benoît Courcet, Virginie Carmignac, Philippine Garret $\mathbb{D}^{0}$, Didier Bessis, Odile Boute, Alain Bron (1), Guillaume Captier, Esther Carmi, Bernard Devauchelle, David Geneviève, Catherine Gondry-Jouet, Laurent Guibaud, Arnaud Lafon, Michèle Mathieu-Dramard, Julien Thevenon, William B. Dobyns, Geneviève Bernard, Satyamaanasa Polubothu, Francesca Faravelli, Veronica A. Kinsler, Christel Thauvin, Laurence Faivre, M. Elizabeth Ross (i) and Jean-Baptiste Rivière (1)

Correction to: Nature Genetics 51: 1438-1441 https://doi.org/10.1038/s41588-019-0498-4, published online 30 September 2019.

In the version of this article initially published, authors Bénédicte Demeer and Bernard Devauchelle were missing the affiliation EA CHIMERE-7516, Universite Picardie Jules Verne, Amiens, France. The error has been corrected in the HTML and PDF versions of the article. 